\title{
Simple Detection Method of Biogenic Amines in Decomposed Fish by Intramolecular Excimer Fluorescence
}

\author{
Hirofumi Nishikawa, Tatsuya Tabata, Seiichi Kitani* \\ Health Service Center, Tokyo University of Marine Science and Technology, Konan, Japan. \\ Email: *drkitani@kaiyodai.ac.jp
}

Received May $30^{\text {th }}, 2012$; revised June $30^{\text {th }}, 2012$; accepted July $7^{\text {th }}, 2012$

\begin{abstract}
Biogenic amines are known to have various biological functions such as not only neurotransmitter and cell proliferation but also food poisoning. Bacterially-decomposed amines such as histamine, agmatine, putrescine, cadaverine, spermidine and spermine cause allergic symptoms. We developed simple method for measurement of polyamine as indicator of food decomposition with a fluorometer by using 4-(1-Pyrene)butyric acid N-hydroxysuccinimide ester (PSE). PSE reacts with primary and secondary amino moieties of polyamines and produces the intramolecular excimer fluorescence. Excimer fluorescence with broad peak at around $470 \mathrm{~nm}$ was clearly detected in linear type biogenic amines such as putrescine, cadaverine, spermidine and spermine at $10 \mathrm{mM}$. However neither histamine nor trimethylamine altered the fluorescence. Decomposed sardine and mackerel by improper storage showed stronger intensity than fresh ones. Comparing with OPA-method, PSE method was useful for screening biogenic amines present in food, esp. fish since the analysis was simple after one-step purification procedure. An inexpensive system which can rapidly detect biogenic amines from food is necessary in a medium and small-sized food business. The technique using excimer has potential to realize the high through-put screening system for evaluation of food freshness and is expected to bring the public interests such as food security and safety of consumer.
\end{abstract}

Keywords: 4-(1-Pyrene)butyric Acid N-Hydroxysuccinimide Ester; PSE Excimer Fluorescence; Biogenic Amine; Fish Decomposition; Polyamine; Food Poisoning

\section{Introduction}

Biogenic amines are a group of chemicals synthesized from amino acids. The amines are naturally present in the body, having various biological functions. For instance, monoamines such as catecholamine (adrenaline and dopamine) and tryptamine (serotonin and melatonin) play a role as neurotransmitters [1]. Polyamine, an cyclic or linear organic compound having two or more primary amino groups as shown in Figure 1, are involved with growth and cell proliferation [2-4]. The heterocyclic amine such as histamine and tertiary amine such as trimethylamine also have biological functions.

Biogenic amines such as histamine, putrescine, cadaverine, agmatine, spermidine and spermine are also found in seafood, meat and cheese, which are generated by bacterial enzymatic decarboxylase of free amino acid $[2,5,6]$. For instance, histamine is synthesized from histidine by histidine decarboxylase (HDC) secreted from microbes belonging to gram-negative bacteria (i.e., Morganella morganii, Enterobacter aerogenes, Photobacterium phosphoreum, Raoultella planticola, etc.) and gram-

${ }^{*}$ Corresponding author. positive bacteria such as lactic acid bacteria [7]. Similarly, other amino acid specific decarboxylases by various spoiling bacterium synthesize putrescine from ornithine, cadaverine from lysine, and spermidine and spermine from arginine, respectively. The composition of these biogenic amines depends on quantity of each amino acid in foods.

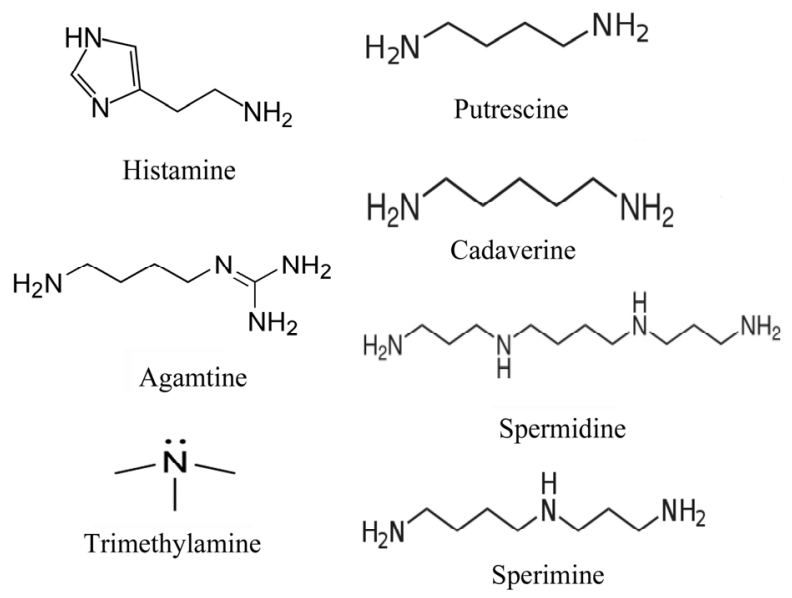

Figure 1. Structure of biogenic amines used in this study. 
In fact the fish such as families Scombridae (e.g. tuna and mackerel) and some of non-scombroid fish (e.g. mahi-mahi, sardines, pilchards, anchovies, herring, marlin and bluefish) are prone to accumulate histamine because of containing high levels of free histidine in these fish, [8]. On the other hand, seafood such as cephalopods (e.g. squid, octopus and cuttlefish), crustaceans (e.g. shrimp and crab) and bivalve mollusks mainly produce putrescine and cadaverine but not histamine during decomposition [9-11].

The ingestion of exogenous huge amounts of amines in decomposed food results in food poisoning. Especially, histamine at the concentrations higher than $500 \mathrm{ppm}$ causes food poisoning [12]. The symptom typically occurs within from $10 \mathrm{~min}$ to $1 \mathrm{~h}$ in case of consumption of poisonous fish, and resembles Type-I allergy such as hives, hot rash, flushing, nausea and facial swelling [13]. Recovery is usually completed within $24 \mathrm{~h}$, but in rare cases can last for days [14]. Rarely are serious cardiac and respiratory complications observed for patients with preexisting disease conditions [15]. Histamine is metabolized by various enzymes such as monoamine-oxidase (MAO) and diamine oxidase (DAO) [16]. Therefore people who are deficient in their enzymatic function owing to genetic causes or through inhibition by taking antidepression medicines such as monoamine oxidase inhibitors (MAOIs) are more susceptible to histamine toxicity $[2,17]$. The other aliphatic amines such as putrescine and cadaverine are known to enhance histamine toxicity [18]. The mechanism of amplification is thought as a result of inhibition of DAO [19] and increase of histamine absorption [20]. Release of endogenous histamine from mast cells by scombroid toxin is also suggested to associate with allergy-like symptoms [21]. There are supportive reports that spermine is known to enhance IgEmediated degranulation [22] and induce the release through G-protein activation in mast cells [23]. Polyamines are present in mast cell secretory granules and associate with granule homeostasis [24], suggesting the synergistic or additive enhancement of allergic symptoms.

From a standpoint of food toxicity and hygiene, there have been developed the various analytic methods of biogenic amines such as thin-layer chromatography, gas chromatography, HPLC as well as capillary electrophoretic methods. Because most amines show neither UV absorption nor fluorescence, most methods require the derivatization, for instance dansyl chloride [25], dansyl chloride [26], O-phthalaldehyde (OPA) [27], 6-aminoquinolyl-N-hydroxysuccinimidyl carbamate [28]. OPA method mentioned above, generally established as simple and high sensitive analysis of histamine, requires troublesome pretreatment to remove impurity. On the other hand, formation of intramolecular excimer by 4-(1-pyrene)butyric acid N-hydroxysuccinimide ester (PSE) is re- ported to selectively detect biogenic amines with simple pretreatment [29]. PSE reacts with primary and secondary amino moieties of polyamines in weakly alkaline environment, which produces intramolecular excimerforming fluorescence with wavelength region (450 - 520 $\mathrm{nm}$ ) longer than the emission from PSE monomer (360 $420 \mathrm{~nm}$ ) [30]. 1-Pyrenebutyryl Chloride (PBC) is known as other derivative for analysis polyamine using excimer fluorescence [31]. Marks et al. reported the analysis of putrescine and cadaverine in seafood by HPLC using excimer fluorescence method, but did not monitor the increase of the amines with decomposition [32]. In their reports, spermine and spermidines, mast cell secretagogues, were not analyzed, which is not adequately presented in connection with allergy-like food poisoning.

Analysis method by using HPLC is superior in high resolution and sensitivity, but is not suitable for screening of a mass of samples. Furthermore training of technician and start-up of the system and running cost are so expensive for a medium and small-sized fishery business. Therefore we developed simple method to monitor freshness during storage of fish by using spectrofluorometer, which detects excimer fluorescence of PSE labeled polyamines such as putrescine, cadaverine, spermine and spermidine. We also confirmed the association among fish decomposition and increase of excimer fluorescence.

\section{Material and Methods}

\subsection{Reagents}

Histamine, putrescine, spermine, spermidine, agmatine, cadaverine, trimethylamine, $O$-phthalaldehyde, 4-(1-pyrene)butyric acid N-hydroxysuccinimide ester (PSE) were purchased from Sigma (Sigma Aldrich, St. Louis, MO). 1-Pyrenebutyry Chloride (PBC) was purchased from Tronto Research Chemicals Inc., (Ontario, Canada). The purity of all reagents was HPLC grade or highest quality.

\subsection{Preparation of Solutions}

Histamine, putrescine, spermine, spermidine, agmatine, cadaverine and trimethylamine were prepared in $1 \mathrm{M}$, and diluted to the required concentration by HPLC grade water (Wako pure chemical, Osaka, Japan) before use. OPA solution was prepared by dissolving $20 \mathrm{mg}$ OPA into $10 \mathrm{~mL}$ of ethanol. PSE solution was prepared in 5 $\mathrm{mM}$ by acetonitrile of highest grade. $\mathrm{PBC}$ solution was prepared in $30 \mathrm{mM}$ in DMSO and diluted to $6 \mathrm{mM}$ by acetonitrile. All the solutions were stored in polypropylene micro tubes protected from light and stored at $-20^{\circ} \mathrm{C}$, and used within 1 week.

\subsection{Preparation of Extracts}

Fresh sardine Sardinops melanostictus (Temminck and Schlegel, 1846) and mackerel Scomber japonicus (Hout- 
tuyn, 1782) were purchased from a supermarket in Tokyo. The fish in polystyrene foam box containing ice were immediately transported to the laboratory. Some fish were stored at $30^{\circ} \mathrm{C}$ for $24 \mathrm{~h}$ and $72 \mathrm{~h}$ to be decomposed by microbial decarboxylation. After peeling, $5.0 \mathrm{~g}$ of fish meat was homogenated with $8.0 \mathrm{~mL}$ of water and centrifuged at $430 \times \mathrm{g}$ for $10 \mathrm{~min}$ at $4^{\circ} \mathrm{C}$. The supernatant volume was re-adjusted to $8.0 \mathrm{~mL}$ and mixed with 2.4 $\mathrm{mL}$ of $30 \%$ trichloroacetic acid, followed by centrifugation at $13,000 \times \mathrm{g}$ for $10 \mathrm{~min}$ to remove crude protein. The supernatant was filtered with $0.45 \mu \mathrm{m}$ syringe filter DIS-MIC (Advantec, Japan), stored at $-80^{\circ} \mathrm{C}$ until analysis. As control, fresh fish extracts were prepared just after thawing. For OPA-derivatization, the extract was further purified by mixing $3 \mathrm{~N} \mathrm{NaOH}$ containing $100 \mathrm{mg} / \mathrm{mL}$ of $\mathrm{NaCl}$ with $\mathrm{N}$-butanol at ratio of 20:25:2 (vol/vol) followed by centrifugation at $10,000 \times \mathrm{g}$ for $10 \mathrm{~min}$. The supernatant was added with $0.12 \mathrm{~N} \mathrm{HCl}$ and $\mathrm{N}$-heptane at 5:3:9 ( $\mathrm{vol} / \mathrm{vol}$ ). After shaking, the lower phase was collected and stored at $-80^{\circ} \mathrm{C}$ until analysis.

\subsection{Derivatization Method}

OPA derivatization was performed as follow. $1200 \mu \mathrm{L}$ of purified fish extract was mixed with $60 \mu \mathrm{L}$ of OPA solution and $240 \mu \mathrm{L}$ of $1 \mathrm{~N} \mathrm{NaCl}$. After incubation at $4{ }^{\circ} \mathrm{C}$ for $40 \mathrm{~min}, 120 \mu \mathrm{L}$ of $3 \mathrm{~N} \mathrm{HCl}$ was added. PSE derivatization was performed as described with slight modification [33]. Briefly, $150 \mu \mathrm{L}$ of each amine standard solution or fish solution were mixed with $1200 \mu \mathrm{L}$ of $5 \mathrm{mM}$ PSE solution and $300 \mu \mathrm{L}$ of $1.5 \mathrm{mM}$ potassium carbonate in 2-mL screw cap polypropylene tubes (Axygen scientific, Unicon city, California). The tubes were tightly sealed and heated for $90 \mathrm{~min}$ in boiling water. The reacted solutions were diluted 1000 times with acetonitrile to decrease emission from monomer. PBC-labeling was performed as described, with slight modification [31]. Briefly, sample solutions, $6 \mathrm{mM}$ PBC solution and $0.5 \mathrm{mM}$ potassium carbonate were mixed at ratio (volume) of 10:20:1 (600 $\mu \mathrm{L}: 1200 \mu \mathrm{L}: 60 \mu \mathrm{L}$ ), followed by incubation at $25^{\circ} \mathrm{C}$ for $5 \mathrm{~min}$. The fluorescence intensity from OPA-, PSE, PBCderivatized biogenic amines were measured by emission $350-600 \mathrm{~nm}$ and excitation of 340,350 and $355 \mathrm{~nm}$, respectively.

\subsection{Equipment and Analysis}

Fluorescence spectral was measured with RF-5300 spectrofluorometer (Shimadzu, Tokyo, Japan) in $10 \times 10 \mathrm{mM}$ quartz cuvette. Spectral band width of $1.5 \mathrm{~nm}$ was used for both the excitation and emission. Data were collected and analyzed with Ion Prove Program (version 1.00) (Shimadzu, Tokyo, Japan).

\section{Results and Discussion}

\subsection{Fluorescence from OPA Derivatized Histamine and Decayed Fish}

We investigated the fluorescence from OPA labeled histamine at the concentration between $10 \mathrm{pM}-1 \mathrm{M}$, and found peak fluorescence at $445 \mathrm{~nm}$ with dose-dependent increase in a range of $100 \mathrm{~nm}-100 \mu \mathrm{m}$ (Figure 2(a)).

Fluorescence intensity from distilled water, $100 \mathrm{~nm}$ and $1 \mathrm{M}$ of histamine were 1.03, 1.56 and 4.31, respectively. The solution of histamine above $1 \mathrm{mM}$ was yellow color, and therefore it is impossible to take proper intensity. We also measured OPA-derivatized fish extracts prepared from fresh sardine, mackerel and their spoiled fishes incubated at $30^{\circ} \mathrm{C}$ for 3 days. Both spoiled sardine and mackerel obviously increased fluorescence compared with fresh one, suggesting the histamine production through decomposition (Figure 2(b)).

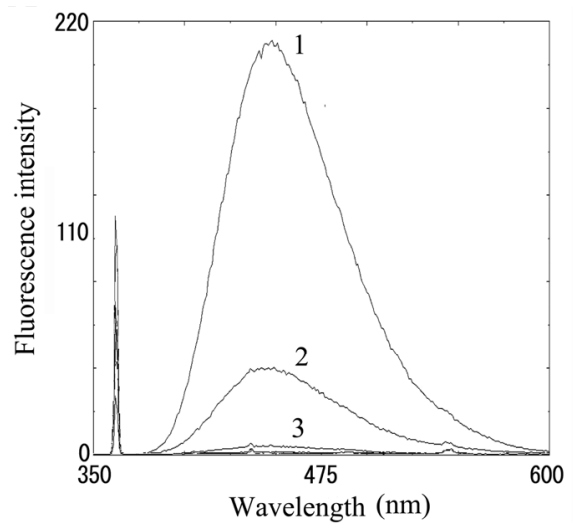

(a)

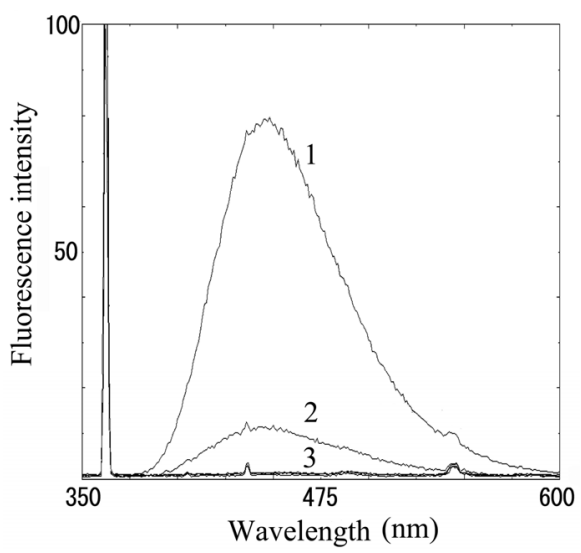

(b)

Figure 2. Fluorescence from OPA-derivatized histamine. (a) Fluorescence intensity in histamine solution. Number 1 - 3 indicate 100, 10 and $1 \mu \mathrm{M}$ of histamine stock solutions, respectively; (b) Fluorescence intensity in fish extract. Number 1 - 3 indicate (1) mackerel (72 h incubation), (2) sardine (72 $\mathrm{h}$ incubation) and (3) both fresh sample, respectively. 


\subsection{Fluorescence from Biogenic Amines Labeled with PSE}

We next analyzed the excimer fluorescence from biogenic amines mainly produced in decayed fish. Each concentration of amine standard solutions $(0,0.1,1,10$ $\mathrm{mM}$ ) was reacted with weakly alkalinized PSE solution, and diluted 1000-times with acetonitrile to minimize intermolecular excimer. Neither histamine nor trimethylamine altered the fluorescence (Figures 3(a) and (b)). Agmatine minimally increased fluorescence around 450 nm (Figure 3(c)). Excimer fluorescence with broad peak at around $470 \mathrm{~nm}$ was clearly appeared in putrescine, cadaverine, spermidine and spermine at the concentration of $10 \mathrm{mM}$ (Figures 3(d)-(g)). As for PBC-derivatized amines, there is no change of peak and intensity (data not shown). Although the detection of PSE-derivatized histamine from rat brain by using HPLC was reported [33], we could detect the excimer fluorescence from only lin ear type diamines, namely putrescine, cadaverine, spermidine and spermine (structures shown in Figure 1, right side), but not histamine in our analysis. Trimethylamine, itself tertiary amine, did not emit the fluorescence. In addition, increase of the exicimer fluorescence seen in PSE-labeled agmatine seems false-positive, since stokes shift was smaller than that of other polyamine. In case of amine having primary amine at the branched side chain,

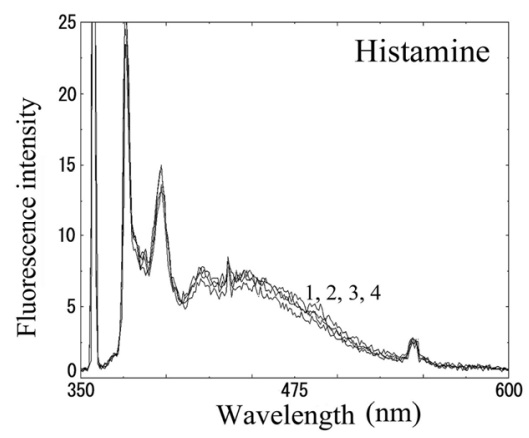

(a)

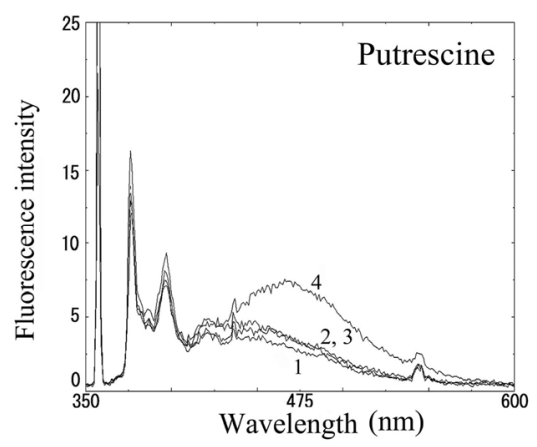

(d)

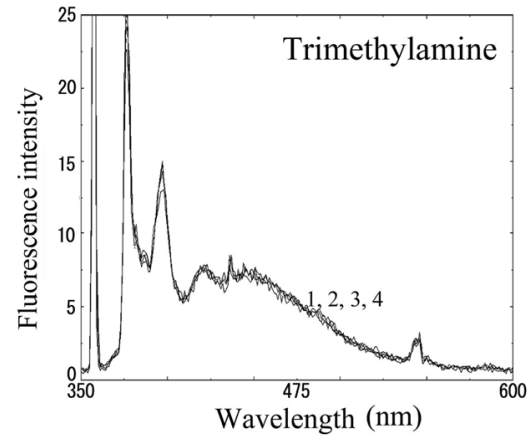

(b)

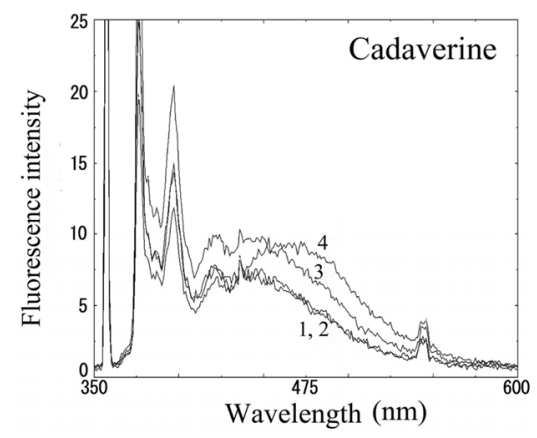

(e)

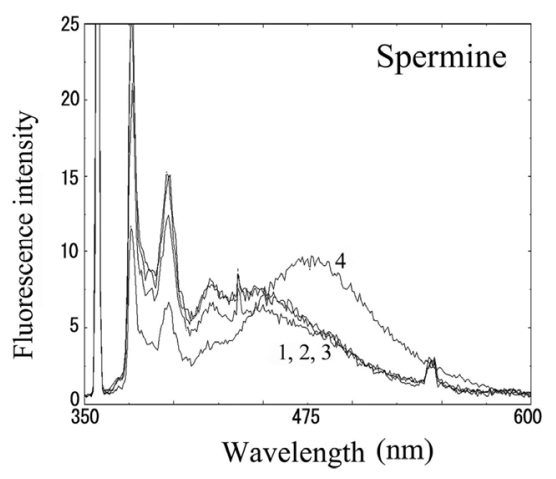

(g)

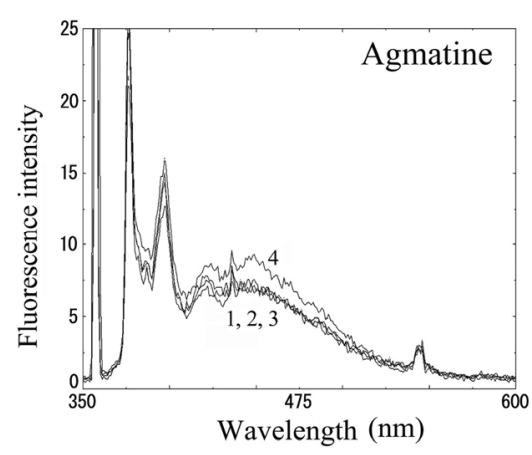

(c)

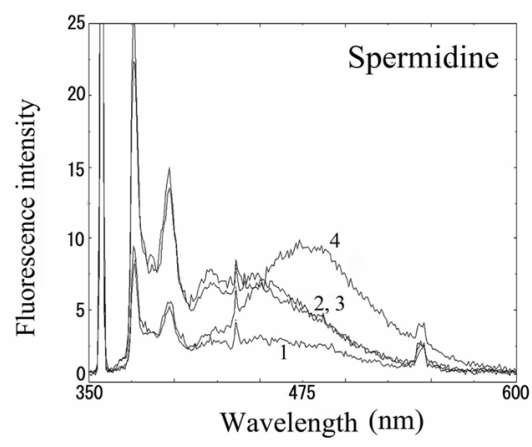

(f)

Number 1 - 4 indicate $0,0.1,1$ and $10 \mathrm{mM}$ of stock solutions, respectively. PSE-derivatized solution was diluted 1000 times and measured by excitation 355 nm and emission $300-600 \mathrm{~nm}$.

Figure 3. Fluorescence from PSE-derivatized biogenic amines. 
normally excited dimer may not be composed because of an inadequate tertiary structure. In fact, it is known that two or more fluorophores in a molecule cause quenching of fluorescence, called self-quenching. Therefore, it is supposed that only linear diamines containing primary amines at both ends are detectable with PSE in our method.

\subsection{Evaluation of Fish-Freshness by PSE Excimer-Fluorescence}

Freshness of fish was evaluated by measurement of excimer fluorescence from PSE-derivatized fish extract after one-step purification with trichloroacetic acid. The

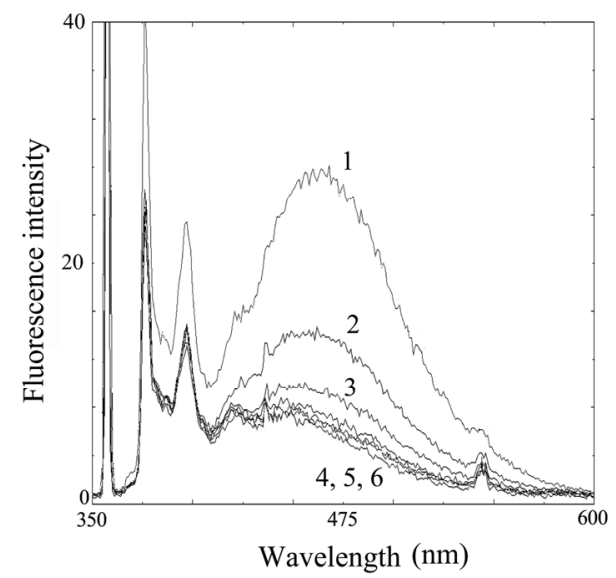

(a)

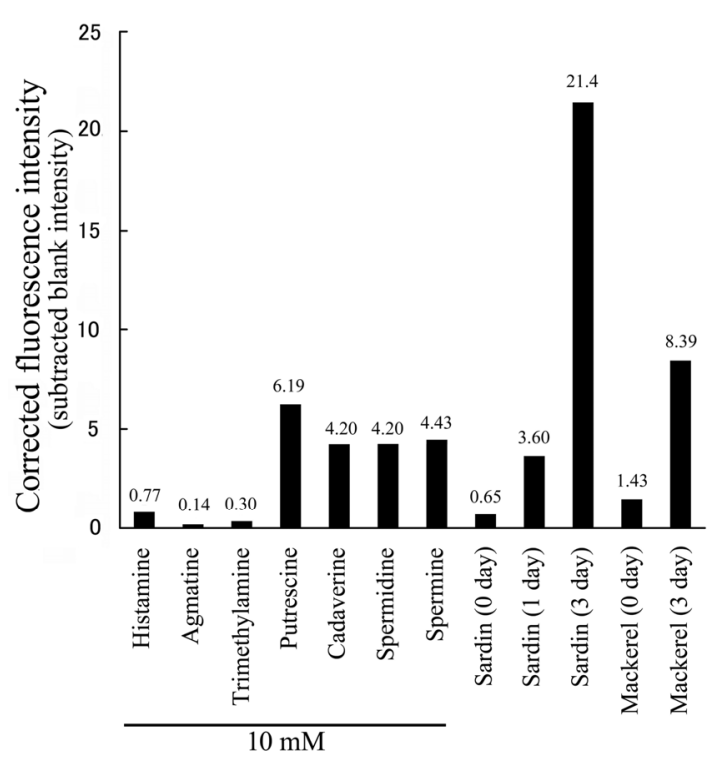

(b)

Figure 4. Analysis of decomposed fish with PSE-derivatization. (a) Fluorescence intensity from fish extract derivatized with PSE. Number 1 - 6 indicate (1) sardine $(72 \mathrm{~h}$ incubation), (2) mackerel (72 h), (3) sardine (24 h), (4) mackerel (0 h), (5) sardine (0 h) and (6) blank water, respectively; (b) Corrected fluorescence intensity by subtraction of blank. fluorescence wave profile in the extracts prepared from fresh fish was the same as water (Figure 4(a), line 4-6). Spoiled mackerel released the significant emission with broad peak at around $470 \mathrm{~nm}$ (Figure 4(a), line 2). The fluorescence intensity was also increased in the extract from sardine incubated for $72 \mathrm{~h}$, and was higher than that from that for $24 \mathrm{~h}$ (Figure 4(a), line 1 and 3).

Figure 4(b) shows the fluorescence intensity value of each samples subtracted that of blank (HPLC grade water). The fluorescence intensity in fresh sardine and mackerel were 0.65 and 1.43. Similarly, histamine, agmatine and trimethylamine showed the intensity of 0.77 , 0.14 and 0.30 , respectively. Mackerel incubated for $72 \mathrm{~h}$ at $30^{\circ} \mathrm{C}$ increased the intensity to 8.39 . In sardine, the intensity in $24 \mathrm{~h}$ and $72 \mathrm{~h}$ at $30^{\circ} \mathrm{C}$ incubation were 3.60 and 21.4 , showing polyamine production during improper storage. Therefore, polyamine in fish extract can be estimated as 1 - $10 \mathrm{mM}$ level of putrescine, cadaverine, spermidine and spermine, suggesting significant detection level and practical application for evaluation of freshness (Figure 4(b)).

\section{Conclusion}

Biogenic amines are involved with food poisoning. In this study, we demonstrated that PSE-derivatized excimer fluorescence was detected in linear polyamines such as putrescine, cadaverine, spermidine and spermine. We also demonstrated here the increase of fluorescence in decomposed sardine and mackerel fish by PSE derivatization just by removing proteins or debris with trichloroacetic acid, which is simpler than OPA method. PSE did not give intramolecular excimer fluorescence from heterocyclic amine histamine. This inexpensive and simple technique will be useful for a medium and smallsized food business, and also brings the public interests in context of food security and safety of consumer.

\section{Acknowledgements}

This work was supported in part by Grant-in-Aid for Scientific Research(C) by Japan Society for the Promotion of Science.

\section{REFERENCES}

[1] K. Hyland, "Neurochemistry and Defects of Biogenic Amine Neurotransmitter Metabolism," Journal of Inherited Metabolic Disease, Vol. 22, No. 4, 1999, pp. 353-363. doi:10.1023/A:1005587719505

[2] T. H. Jover, M. I. Pulido, M. T. V. Nogues, A. M. Font and M. C. V. Carou, "Biogenic Amine and Polyamine Contents in Meat and Meat Products," Journal of Agricultural and Food Chemistry, Vol. 45, No. 6, 1997, pp. 2098-2102. doi:10.1021/jf960790p

[3] P. Kalac, "Biogenic Amine and Polyamine Contents in 
Meat and Meat Products," Journal of Applied Biomedicine, Vol. 7, No. 2, 2009, pp. 65-74.

[4] M. K. Kim, J. H. Mah and H. J. Hwang, "Biogenic Amine Formation and Bacterial Contribution in Fish, Squid and Shellfish," Food Chemistry, Vol. 116, No. 1, 2009, pp. 87-95. doi:10.1016/j.foodchem.2009.02.010

[5] I. A. Bulushi, S. Poole, H. Deeth and G. Dykes, "Biogenic Amines in Fish: Roles in Intoxication, Spoilage, and Nitrosamine Formation: A Review," Critical Reviews in Food Science and Nutrition, Vol. 49, No, 4, 2009, pp. 369-377. doi:10.1080/10408390802067514

[6] S. Standara, M. Vesela and M. Drdak, "Determination of Biogenic Amines in Cheese by Ion Exchange Chromatography," Nahrung-Food, Vol. 44, No. 1, 2000, pp. 2831.

doi:10.1002/(SICI)1521-3803(20000101)44:1<28::AID-F OOD28>3.0.CO;2-I

[7] J. M. Landete, B. de las Rivas, A. Marcobal and R. Munoz, "Molecular Methods for the Detection of Biogenic Amine-Producing Bacteria on Foods," International Journal of Food Microbiology, Vol. 117, No. 3, 2007, pp. 258-269. doi:10.1016/j.ijfoodmicro.2007.05.001

[8] J. M. Hungerford, "Scombroid Poisoning: A Review," Toxicon, Vol. 56, No. 2, 2010, pp. 231-243. doi:10.1016/j.toxicon.2010.02.006

[9] L. Prester, T. Orct, L. Macan, J. Vukusic and D. Kipcic, "Determination of Biogenic Amines and Endotoxin in Squid, Musky Octopus, Norway Lobster, and Mussel Stored at Room Temperature," Archives of Industrial Hygiene and Toxicology, Vol. 61, No. 4, 2010, pp. 389-397. doi:10.2478/10004-1254-61-2010-2049

[10] N. Erkan, "Changes in Quality Characteristics during Cold Storage of Shucked Mussels (Mytilus galloprovincialis) and Selected Chemical Decomposition Indicators," Journal of the Science of Food and Agriculture, Vol. 85, No. 15,2005 , pp. 2625-2630. doi:10.1002/jsfa.2331

[11] R. A. Benner, W. F. Staruszkiewicz and W. S. Otwell, "Putrescine, Cadaverine, and Indole Production by Bacteria Isolated from Wild and Aquacultured Penaeid Shrimp Stored at 0, 12, 24, and 36 Degrees C," Journal of Food Protection, Vol. 67, No. 1, 2004, pp. 124-133.

[12] V. E. Gonzaga, A. G. Lescano, A. A. Huaman, G. SalmonMulanovich and D. L. Blazes, "Histamine Levels in Fish from Markets in Lima, Peru," Journal of Food Protection, Vol. 72, No. 5, 2009, pp. 1112-1115.

[13] S. L. Taylor, J. E. Stratton and J. A. Nordlee, "Histamine Poisoning (Scombroid Fish Poisoning): An Allergy-Like Intoxication," Journal of Toxicology Clinical Toxicology, Vol. 27, No. 4-5, 1989, pp. 225-240. doi: $10.3109 / 15563658908994420$

[14] S. L. Taylor, "Histamine Food Poisoning: Toxicology and Clinical Aspects," Critical Reviews in Toxicology, Vol. 17, No. 2, 1986, pp. 91-128. doi:10.3109/10408448609023767

[15] F. E. Russell and Z. Maretić, "Scombroid Poisoning: Mini-Review with Case Histories," Toxicon, Vol. 24, No. 10, 1986, pp. 967-973. doi:10.1016/0041-0101(86)90002-4
[16] T. Toyo'oka, "Separation Assay of Histamine and Its Metabolites in Biological Specimens," Biomedical Chromatography, Vol. 22, No. 9, 2008, pp. 919-930. doi:10.1002/bmc. 1027

[17] M. Miki, T. Ishikawa and H. Okayama, "An Outbreak of Histamine Poisoning after Ingestion of the Ground Saury Paste in Eight Patients Taking Isoniazid in Tuberculous Ward," Internal Medicine, Vol. 44, No. 11, 2005, pp. 1133-1136. doi:10.2169/internalmedicine.44.1133

[18] L. F. Bjeldanes, D. E. Schutz and M. M. Morris, "On the Aetiology of Scombroid Poisoning: Cadaverine Potentiation of Histamine Toxicity in the Guinea-Pig," Food and Cosmetics Toxicology, Vol. 16, No.2, 1978, pp. 157-159. doi:10.1016/S0015-6264(78)80196-5

[19] J. L. Mongar, "Effect of Chain Length of Aliphatic Amines on Histamine Potentiation and Release," British Journal of Pharmacology and Chemotherapy, Vol. 12, No. 2, 1957, pp. 140-148.

[20] D. E. Lyons, J. T. Beery, S. A. Lyons and S. L. Taylor, "Cadaverine and Aminoguanidine Potentiate the Uptake of Histamine in Vitro in Perfused Intestinal Segments of Rats," Toxicology and Applied Pharmacology, Vol, 70, No. 3, 1983, pp. 445-458. doi:10.1016/0041-008X(83)90162-X

[21] P. Ijomah, M. N. Clifford, R. Walker, J. Wright, R. Hardy and C. K. Murray, "The Importance of Endogenous Histamine Relative to Dietary Histamine in the Aetiology of Scombrotoxicosis," Food Additives and Contaminants, Vol. 8, No. 4, 1991, pp. 531-542. doi:10.1080/02652039109374005

[22] M. Kurosawa, D. Uno and S. Kobayashi, "Naturally Occurring Aliphatic Polyamines-induced Histamine Release from Rat Peritoneal Mast Cells," Allergy, Vol. 46, No. 5, 1991, pp. 349-354. doi:10.1111\%2Fj.1398-9995.1991.tb00597.x

[23] M. Mousli, J. L. Bueb, B. Rouot, Y. Landry and C. Bronner, "G-proteins as Targets for Non-Immunological Histamine Releasers," Inflammation Research, Vol. 33, No. 1-2, 1991, pp. 81-83. doi:10.1007\%2FBF01993132

[24] G. García-Faroldi, C. E. Rodríguez, J. L. Urdiales, J. M. Pérez-Pomares, J. C. Dávila, G. Pejler, F. Sánchez-Jiménez and I. Fajardo, "Polyamines Are Present in Mast Cell Secretory Granules and Are Important for Granule Homeostasis," PLoS ONE, Vol. 5, No. 11, 2010, p. e.15071. doi:10.1371\%2Fjournal.pone.0015071

[25] J. Lapa-Guimarães and J. Pickova, "New Solvent Systems for Thin-layer Chromatographic Determination of Nine Biogenic Amines in Fish and Squid," Journal of Chromatography A, Vol. 1045, No. 1-2, 2004, pp. 223232. doi:10.1016\%2Fj.chroma.2004.06.014

[26] R. Romero, M. Sánchez-Viñas, D. Gázquez and M. G. Bagur, "Characterization of Selected Spanish Table Wine Samples According to Their Biogenic Amine Content from Liquid Chromatographic Determination," Journal of Agricultural and Food Chemistry, Vol. 50, No. 16, 2002, pp. 4713-4717. doi:10.1021\%2Fjf025514r

[27] R. P. Siraganian, "An Automated Continuous-flow System for the Extraction and Fluorometric Analysis of Histamine," Analytical Biochemistry, Vol. 57, No. 2, 1974, 
pp. 383-394.

doi:10.1016\%2F0003-2697\%2874\%2990093-1

[28] A. Kovács, L. Simon-Sarkadi and K. Ganzler, "Determination of Biogenic Amines by Capillary Electrophoresis," Journal of Chromatography A, Vol. 836, No. 2, 1999, pp. 305-313.

doi: $10.1016 \% 2 F S 0021-9673 \% 2898 \% 2900912-1$

[29] T. Yoshitake, F. Ichinose, H. Yoshida, K. Todoroki, J. Kehr, O. Inoue, H. Nohta and M. Yamaguchi, "A Sensitive and Selective Determination Method of Histamine by HPLC with Intramolecular Excimer-Forming Derivatization and Fluorescence Detection," Biomedical Chromatography, Vol. 17, No. 8, 2003, pp. 509-516. foi: $10.1002 \% 2 \mathrm{Fbmc} .264$

[30] H. Nohta, H. Satozono, K. Koiso, H. Yoshida, J. Ishida and M. Yamaguchi, "Highly Selective Fluorometric Determination of Polyamines Based on Intramolecular Excimer-Forming Derivatization with a Pyrene-Labeling Reagent," Analytical Chemistry, Vol. 72, No. 17, 2000, pp. 4199-4204. doi: $10.1021 \% 2 \mathrm{Fac} 0002588$
[31] H. Yoshida, H. Harada, Y. Nakano, H. Nohta, J. Ishida and M. Yamaguchi, "Liquid Chromatographic Determination of Polyamines in Human Urine Based on Intramolecular Excimer-Forming Fluorescence Derivatization Using 4-(1-Pyrene)butanoyl Chloride," Biomedical Chromatography, Vol. 18, No. 9, 2004, pp. 687-693. doi: $10.1002 \% 2$ Fbmc. 377

[32] H. S. M. Rupp and C. R. Anderson, "Determination of Putrescine and Cadaverine in Seafood (Finfish and Shellfish) by Liquid Chromatography Using Pyrene Excimer Fluorescence," Journal of Chromatography A, Vol. 1094, No. 1-2, 2005, pp. 60-69. doi:10.1016\%2Fj.chroma.2005.07.088

[33] T. Yoshitake, M. Yamaguchi, H. Nohta, F. Ichinose, H. Yoshida, S. Yoshitake, K. Fuxe and J. Kehr, "Determination of Histamine in Microdialysis Samples from Rat Brain by Microbore Column Liquid Chromatography Following Intramolecular Excimer-Forming Derivatization with Pyrene-Labeling Reagent," Journal of Neuroscience Method, Vol. 127, No. 1, 2003, pp. 11-17. doi: $10.1016 \% 2 \mathrm{FS} 0165-0270 \% 2803 \% 2900097-9$ 